\title{
Erratum to: A novel planar optical sensor for simultaneous monitoring of oxygen, carbon dioxide, $\mathrm{pH}$ and temperature
}

\author{
Sergey M. Borisov • Roman Seifner • Ingo Klimant
}

Received: 28 March 2012 / Accepted: 28 March 2012 / Published online: 24 April 2012

(C) Springer-Verlag 2012

\section{Erratum to: Analytical and Bioanalytical Chemistry DOI 10.1007/s00216-010-4617-4}

The authors regret that the equation 1 for the calculation of the luminescence decay times was reported with an error. The correct equation used for the calculations is:

$\tau=\frac{1}{2 \pi}\left(\frac{\mathrm{f}_{1}{ }^{2}-\mathrm{f}_{2}{ }^{2} \pm \sqrt{\left(\mathrm{f}_{2}{ }^{2}-\mathrm{f}_{1}{ }^{2}\right)^{2}-4\left(\cot \Phi_{2} \cdot \mathrm{f}_{2} \cdot \mathrm{f}_{1}{ }^{2}-\cot \Phi_{1} \cdot \mathrm{f}_{1} \cdot \mathrm{f}_{2}{ }^{2}\right)\left(\cot \Phi_{2} \cdot \mathrm{f}_{2}-\cot \Phi_{1} \cdot \mathrm{f}_{1}\right)}}{2\left(\cot \Phi_{2} \cdot \mathrm{f}_{2} \cdot \mathrm{f}_{1}{ }^{2}-\cot \Phi_{1} \cdot \mathrm{f}_{1} \cdot \mathrm{f}_{2}{ }^{2}\right)}\right)$

This error is also contained in the following publications: Kocincova AS, Borisov SM, Krause C, Wolfbeis OS (2007) Anal Chem 79: 8486-8493 (reference 16)

Borisov SM, Gatterer K, Klimant I (2010) Analyst 135: 1711-1717 (reference 19)

Vasylevska GS, Borisov SM, Krause C, Wolfbeis OS (2006) Chem Mater 18: 4609-4616 (reference 20)

Borisov SM, Neurauter G, Schroeder C, Klimant I, Wolfbeis OS (2006) Appl Spectrosc 60: 1167-1173 (reference 29)

Kocincova AS, Nagl S, Arain S, Krause C, Borisov SM, Arnold M, Wolfbeis OS (2008) Biotechnol Bioeng 100: 430-438

Borisov SM, Vasylevska AS, Krause C, Wolfbeis OS (2006) Adv Funct Mater 16: 1536-1542

In all cases the correct equation was used for the data analysis so none of the conclusions of the papers are affected. The authors apologize for this error and for any confusion which it caused.

The online version of the original article can be found at http://dx.doi.org/ 10.1007/s00216-010-4617-4.

S. M. Borisov $(\bowtie) \cdot$ R. Seifner $\cdot$ I. Klimant

Institute of Analytical Chemistry and Food Chemistry, Graz

University of Technology,

Stremayrgasse 9,

8010 Graz, Austria

e-mail: sergey.borisov@tugraz.at 